\title{
Genetic Variability, Heritability and Genetic Advance Study in Bread Wheat Genotypes (Triticum aestivum L.)
}

\author{
Endashaw Girma Seyoum ${ }^{1, *}$, Alemnesh Sisay ${ }^{2}$ \\ ${ }^{1}$ Wheat Breeder Crop Research Program, Ethiopian Institute of Agriculture Research, Holetta Research Center, Addis Ababa, Ethiopia \\ ${ }^{2}$ Natural Resource Management Research Program, Ethiopian Institute of Agriculture Research, Holetta Research Center, Addis Ababa, \\ Ethiopia
}

\section{Email address:}

endashaw.girma11@gmail.com (E. G. Seyoum), sisayalemnesh@gmail.com (A. Sisay)

${ }^{*}$ Corresponding author

\section{To cite this article:}

Endashaw Girma Seyoum, Alemnesh Sisay. Genetic Variability, Heritability and Genetic Advance Study in Bread Wheat Genotypes (Triticum aestivum L.). Advances in Bioscience and Bioengineering. Vol. 9, No. 3, 2021, pp. 81-86. doi: 10.11648/j.abb.20210903.13

Received: July 22, 2021; Accepted: August 13, 2021; Published: August 26, 2021

\begin{abstract}
Wheat (Triticum aestivum L.) is a high-yielding crop with a wide range of adaptability, and it is the world's and Ethiopia's principal source of food. In Ethiopia, however, wheat productivity has increased in recent years. Due to abiotic like heat, drought, frost and others and biotic like rusts (Stem, yellow and leaf), Septoria, fusarium and others causes, it is still quite low when compared to other wheat-producing countries. The objectives were to test variability of genotypic and phenotypic and also heritability and genetic advance in bread wheat genotypes. Hence, in this studied conducted on 30 bread wheat genotypes of yield and associated traits was assessed. A trial was undertaken Holetta in Ethiopia in 2018/19 cropping season. The materials were tested using a three-replication alpha lattice pattern. Data on yield and associated traits were analyzed using SAS versions 9.3 software. The heritability estimates for 1000 kernel weight were found to be very high, at 81.14 percent. The trait 1000 kernel weight was also shown to have a high heritability couple with a high genetic advance as a percentage of the mean. So it concluded that 1000 kernel weight may be targeted as the selection criteria for the grain yield improvement However, further study needs to be conducted the future bread wheat breeding effort should be focus on varietal development.
\end{abstract}

Keywords: Bread Wheat, Heritability, Genetic Advance

\section{Introduction}

Wheat production in the world is virtually the two types of modern wheat species, viz. Tetraploid (T. turgidum sub sp. durum, $2 \mathrm{n}=4 \mathrm{X}=28$ ) and hexaploid (Triticum aestivum $\mathrm{L}$., $2 \mathrm{n}=6 \mathrm{X}=42)$. [31]

Bekele $\mathrm{H}$ reported that wheat can be grown in the Ethiopia's high lands [6], which have been located from $35^{\circ}$ and $42^{\circ} \mathrm{E}$ longitude and $6^{\circ}$ to $16^{\circ} \mathrm{N}$ latitude, at altitudes ranging from 1500 to 3000 meters above sea level. Wheat, on the other hand, grows best at altitudes ranging from 1900 to 2700 meters above sea level.

Wheat is the most essential and crucial food security crop in Ethiopia, according to the report, [7, 22] which is grown by half a million farmers on 1.7 million hectares. It contributes a substantial amount to the country's food and nutritional security. [17] reported that the nationwide average wheat productivity is $2.37 \mathrm{t} / \mathrm{ha}$, which is much lower than the worldwide average of $3.27 \mathrm{t} / \mathrm{ha}$.

A yield gap was ascribed to a lack of better wheat varieties for the country's many agro-ecologies, as well as inadequate cultural practices, poor soil fertility, drought, diseases, and insect pests, among other factors. These are Ethiopia's primary wheat production limitations [18]. Hence, to tackle those limitations it is crucial to create information on the variance of phenotypic and genotypic, genetic advance as well as heritability among wheat varieties.

The number of genetic variation available in the population, as well as the amount to which the desired characteristics are hereditary, are important factors in the success of a breeding effort [23]. Heritability is a measure of how well characteristics are passed on from families to their offspring. It's is commonly employed in the breeding program [15].

The genetic advance is another vital parameter to selection 
[32]. The degree of diversity in wheat breeding material has been assessed using genotypic and phenotypic coefficients of variation, heritability, and genetic progress, establish suitable selection techniques, and forecast breeding progress in improving essential characteristics $[37,32,10]$.

The best conditions for selection are provided by high genetic advancement combined with high heritability estimates [21].

Several authors have revealed the occurrence of variability, heritability, and genetic progress in several yield and associated characteristics of common wheat $[4,11,19$, $27,38]$.

In the research region, however, no variability studies have been undertaken. Furthermore, genetic information in wheat genotypes studied in the nation is confined to grain yield and related characteristics. Such data is critical for the genetic variation progress and future wheat enhancement, both in the area as well as throughout the nation. As a result, the present studies objective was to test variability of genotypic and phenotypic in bread wheat genotypes, and also heritability and genetic advance.

\section{Materials and Methods}

Table 1. Experimental site at Holetta is described in terms of its geographical location.

\begin{tabular}{ll}
\hline Description & Location (Holetta) \\
\hline Altitude $(\mathrm{m}$. a.s.l) & $2400 \mathrm{~m}$. \\
Longitude & $38^{\circ} 29^{\prime} \mathrm{E}$ \\
Latitude & $09^{\circ} 04^{\prime} \mathrm{N}$ \\
Rainfall of mean annual $(\mathrm{mm})$ & 1102 \\
Temperature of mean annual $\left({ }^{\circ} \mathrm{C}\right)$ & 14.23 \\
Soil type & Nitosols \\
\hline
\end{tabular}

Source: [34]

Table 2. Experimental Materials of Bread wheat Genetic improvement Study, 2018.

\begin{tabular}{|c|c|c|c|c|c|}
\hline Plot number & Genotype & Plot number & Genotype & Plot number & Genotype \\
\hline 1 & WANE (Check) & 11 & ETW17-55 & 21 & ETW17-77 \\
\hline 2 & ETW17-3 & 12 & ETW17-56 & 22 & ETW17-78 \\
\hline 3 & ETW17-12 & 13 & ETW17-63 & 23 & ETW17-79 \\
\hline 4 & ETW17-17 & 14 & ETW17-66 & 24 & ETW17-80 \\
\hline 5 & ETW17-20 & 15 & ETW17-68 & 25 & ETW17-81 \\
\hline 6 & ETW17-23 & 16 & ETW17-69 & 26 & ETW17-82 \\
\hline 7 & ETW17-38 & 17 & ETW17-71 & 27 & ETW17-84 \\
\hline 9 & ETW17-49 & 19 & ETW17-75 & 29 & ETW17-88 \\
\hline 10 & ETW17-50 & 20 & ETW17-76 & 30 & LEMU (Check) \\
\hline
\end{tabular}

\subsection{Experimental Design and Data Collected}

The field experiment was carried out with three replications of the Alpha lattice design. The standard plot was used $1.2 \mathrm{~m}$ length by $2.5 \mathrm{~m}$ width of $3 \mathrm{~m}^{2}$ area. A fertilizer rate of $60: 69 \mathrm{~N}_{2}: \mathrm{P}_{2} \mathrm{O}_{5}$ per hectare was suggested, with a seed rate of $150 \mathrm{~kg} / \mathrm{ha}$. All additional crop management methods were similarly implemented to all plots as needed.

Data on agro - morphological traits of wheat genotypes were collected from the parameters grain Yield, 1000 Kernel Weight, hectoliter weight, plant height, days to heading, days to maturity and grain Filling Period.

\subsection{Analysis of Statistical}

Statistical analysis was done using SAS 9.3 [30] and Microsoft Excel. Analysis of variance was used to compare the mean values of all experimental units are presented Table 3 .

The ANOVA for individual location followed the model:

$$
P_{i j k}=\mu+g_{i}+b_{k}(j)+r_{j}+e_{i j k}
$$

Where, Pijk $=$ value of phenotypic $i^{\text {th }}$ genotype $j^{\text {th }}$ replication plus $\mathrm{k}^{\text {th }}$ incomplete block within $\mathrm{j}$ replication; $\mu=$ grand mean; gi $=$ the effect of $i^{\text {th }}$ genotype; $b k(j)=$ the effect of incomplete block $\mathrm{k}$ within replication $\mathrm{j} ; \mathrm{rj}=$ the effect of replication $\mathrm{j}$; and eijk $=$ the residual.

\subsection{Estimation of Genetic Parameters}

The phenotypic and genotypic variance component and genotypic and phenotypic coefficient of variation were predictable based on the method suggested by [9].

$$
\text { Error mean square }(\mathrm{MSe})=\delta^{2} \mathrm{e}
$$

Genotypic variance $\left(\delta^{2} \mathrm{~g}\right), \frac{\mathrm{MSg}-\mathrm{MSe}}{r}$

Where: - MSg: mean square genotype, MSe: Error mean square and $r$ : replication.

Phenotypic variance $\left(\delta^{2} \mathrm{p}\right), \delta^{2} \mathrm{p}=\delta^{2} \mathrm{~g}_{+} \delta^{2 \mathrm{e}}$

$$
\begin{aligned}
& \mathrm{GCV} \%=\sqrt{ } \delta^{2} \mathrm{~g} / \overline{\mathrm{x}} * 100 \\
& \mathrm{PCV} \%=\sqrt{ } \delta^{2} \mathrm{p} / \overline{\mathrm{x}} * 100
\end{aligned}
$$

According to [13] as specified GCV and PCV values were classified $>20 \%$ high, 10 to $20 \%$ moderate and 0 to $10 \%$ low.

\subsection{Heritability (H2B)}

Heritability on plot and plant basis was computed for all traits. Heritability $(\mathrm{H} 2 \mathrm{~B})=\delta^{2} \mathrm{~g} / \delta^{2} \mathrm{p} * 100,[16]$ Where: $\mathrm{H}=$ Broad sense heritability, $\delta^{2} \mathrm{p}=$ Phenotypic variance, $\delta^{2} \mathrm{~g}=$ Genotypic variance.

According to [33], heritability was classified into low: $<40 \%$, medium: 40 to $59 \%, 60$ to $79 \%$ moderately high and $>80 \%$ very high. 


\subsection{Genetic Advance}

At 5\% selection intensity the estimated genetic advance for each trait was calculated with method specified by [3].

$$
\mathrm{GA}=\mathrm{KH} 2 \mathrm{~B} \delta \mathrm{P}
$$

Genetic Advance (GA), the standard selection differential at $5 \%(\mathrm{~K}=2.063)$ selection intensity, $\mathrm{H} 2 \mathrm{~B}$ : heritability $(\mathrm{H} 2 \mathrm{~B})$ and phenotypic standard deviation $(\delta \mathrm{P})$.

\subsection{Genetic Advance as Percent of Mean}

$$
\mathrm{GAM}=\mathrm{GA} / \overline{\mathrm{x}} * 100
$$

Where: GAM: Genetic advance as present of mean, GA: Genetic advance and $\overline{\mathrm{x}}=$ Grand mean.

Genetic advance as present of mean was categorized into low: 0 to $10 \%$, medium: 10 to $20 \%$ and high: $>20 \%$ as suggested by [16].

\section{Result and Discussions}

\subsection{Variance Analysis}

Variance analysis revealed that the genotypes were significant differences for all traits (Table 3). [11, 28, 35] reported that in line with to this studied.

\begin{tabular}{|c|c|c|c|c|c|c|c|c|}
\hline Characters & MSG (29) & MSR (2) & MSB (P) (15) & MSE (43) & Mean & CV (\%) & $\mathbf{R 2}$ & LSD (5\%) \\
\hline DTH & $36.45 * *$ & 20.08 & 9.93 & 10.88 & 65.98 & 4.99 & 0.75 & 5.43 \\
\hline DTM & $10.45 * *$ & 1.48 & 2.34 & 2.51 & 136.42 & 1.16 & 0.81 & 2.61 \\
\hline GFP & $29.3 *$ & 13.68 & 9.24 & 14.53 & 70.44 & 5.41 & 0.67 & 6.28 \\
\hline TKW & $59.38 * *$ & 8.41 & 3.87 & 4.27 & 39.83 & 5.19 & 0.94 & 3.40 \\
\hline HLW & $7.54 * *$ & 0.67 & 1.48 & 1.49 & 78.81 & 1.55 & 0.82 & 2.01 \\
\hline GYLD & $1.45^{* *}$ & $1.74 *$ & $2.27 * *$ & 0.46 & 5.35 & 12.66 & 0.86 & 1.12 \\
\hline
\end{tabular}

Table 3. Variance Analysis for yield and associated traits of wheat genotypes grown in the yield potential trial at Holetta.

Parenthesis indicate degree of freedom, MSG = Mean square genotypes, MSR = Mean Square Replications, MSBR = Mean Square Block within replications, $\mathrm{MSE}=$ Error Mean square, CV $=$ Coefficient of Variance, DTH = Days to Heading, DTM = Days to Maturity, GFP $=$ Grain Filling Period, PHT $=$ Plant Height, TKW $=1000$ Kernel Weight, HLW $=$ Hectoliter Weight, GYLD = Grain Yield $(\mathrm{t} / \mathrm{h})$.

\subsection{The Genotypes of Mean Performance and Range}

The mean performance of 30 genotypes with various traits has been mentioned. The detail information's are presented Table 4

The genotypes for days to $50 \%$ flowering were varied from 57(ETW17-3) to 74 days (Lemu variety) among genotypes. ETW17-77, ETW17-23, ETW17-79 and ETW1756 revealed short list of significantly early in days to heading. Whereas; Most of the genotypes were late maturing with range of 133 (ETW17-55) -141 (ETW17-71) days. ETW17-75, ETW17-17, ETW17-3, ETW17-44, ETW17- 68 and ETW17-88 revealed short list of significantly early in days to maturity.

The genotypes for grain yield were fluctuated from 3.17 t/ha (ETW17-55) to 6.85 t/ha (ETW17-80) among the genotypes. ETW17-80, ETW17-77, ETW17-82, ETW17-63, ETW17-81 and ETW17-86 revealed statically better performed than the standard check Lemu in grain yield. The least grain yield, hectoliter weight, 1000 kernel weight and days to maturity was recorded from ETW17-55 genotype. The detail information are presented Table 4.

Therefore, high variability for seven traits of thirty bread wheat genotypes indicated that there was reasonably sufficient variety to allow plant breeders to pick superior and desired genotypes for further improvement. In general, all of the traits studied had a wide range of variation. [19] reported similar results on bread wheat study.

\begin{tabular}{|c|c|c|c|c|c|c|c|c|}
\hline plot no. & Genotype source & DTH & DTM & GFP & PHT & TKW & HLW & GYLD \\
\hline 1 & WANE & 65.00 & 137.00 & 72.00 & 94.97 & 41.93 & 78.30 & 6.03 \\
\hline 2 & ETW17-3 & 57.00 & 134.00 & 77.00 & 85.00 & 43.99 & 79.47 & 5.86 \\
\hline 3 & ETW17-12 & 64.67 & 134.67 & 70.00 & 89.97 & 38.79 & 76.17 & 4.39 \\
\hline 4 & ETW17-17 & 68.67 & 133.67 & 65.00 & 58.33 & 37.92 & 77.87 & 4.59 \\
\hline 5 & ETW17-20 & 65.00 & 134.67 & 69.67 & 95.57 & 37.53 & 80.47 & 5.63 \\
\hline 6 & ETW17-23 & 62.33 & 135.67 & 73.33 & 88.33 & 34.73 & 81.73 & 4.08 \\
\hline 7 & ETW17-38 & 71.33 & 135.00 & 63.67 & 94.43 & 35.61 & 78.00 & 4.56 \\
\hline 9 & ETW17-49 & 65.00 & 137.00 & 72.00 & 96.70 & 37.05 & 78.87 & 4.11 \\
\hline 10 & ETW17-50 & 64.67 & 138.67 & 74.00 & 97.80 & 41.51 & 80.40 & 5.38 \\
\hline 11 & ETW17-55 & 64.33 & 133.33 & 69.00 & 89.47 & 26.88 & 74.67 & 3.17 \\
\hline 12 & ETW17-56 & 63.33 & 134.67 & 71.33 & 88.90 & 37.71 & 79.90 & 5.05 \\
\hline 13 & ETW17-63 & 68.33 & 137.00 & 68.67 & 96.67 & 42.47 & 79.17 & 6.54 \\
\hline 14 & ETW17-66 & 65.33 & 138.67 & 73.33 & 97.20 & 41.18 & 80.87 & 5.88 \\
\hline 15 & ETW17-68 & 68.67 & 134.00 & 65.33 & 87.10 & 28.30 & 75.50 & 4.57 \\
\hline 16 & ETW17-69 & 65.67 & 138.33 & 72.67 & 90.00 & 46.32 & 80.20 & 6.07 \\
\hline
\end{tabular}

Table 4. Variance Analysis of mean performance for yield as well as associated traits of bread wheat genotypes grown in the yield potential trial at Holetta. 


\begin{tabular}{|c|c|c|c|c|c|c|c|c|}
\hline plot no. & Genotype source & DTH & DTM & GFP & PHT & TKW & HLW & GYLD \\
\hline 17 & ETW17-71 & 72.00 & 140.67 & 68.67 & 100.53 & 42.85 & 79.83 & 5.68 \\
\hline 18 & ETW17-74 & 66.33 & 140.00 & 73.67 & 96.10 & 54.50 & 77.10 & 5.67 \\
\hline 19 & ETW17-75 & 64.67 & 133.67 & 69.00 & 88.87 & 36.04 & 77.43 & 4.72 \\
\hline 20 & ETW17-76 & 64.33 & 135.00 & 70.67 & 94.47 & 47.73 & 79.83 & 5.01 \\
\hline 21 & ETW17-77 & 58.33 & 136.00 & 77.67 & 96.10 & 43.66 & 80.53 & 6.64 \\
\hline 22 & ETW17-78 & 70.67 & 139.67 & 69.00 & 91.67 & 41.21 & 80.97 & 4.54 \\
\hline 23 & ETW17-79 & 62.33 & 138.00 & 75.67 & 90.57 & 43.94 & 79.90 & 5.91 \\
\hline 25 & ETW17-81 & 68.33 & 138.00 & 69.67 & 96.10 & 44.22 & 78.53 & 6.50 \\
\hline 26 & ETW17-82 & 64.00 & 137.33 & 73.33 & 90.57 & 43.89 & 77.50 & 6.58 \\
\hline 27 & ETW17-84 & 66.33 & 135.67 & 69.33 & 80.57 & 37.14 & 76.23 & 5.52 \\
\hline 28 & ETW17-86 & 64.67 & 136.33 & 71.67 & 93.37 & 39.46 & 78.93 & 6.38 \\
\hline 29 & ETW17-88 & 68.67 & 134.00 & 65.33 & 90.57 & 34.65 & 78.37 & 4.56 \\
\hline \multirow[t]{3}{*}{30} & LEMU & 74.33 & 139.00 & 64.67 & 97.23 & 37.90 & 79.87 & 6.09 \\
\hline & $\operatorname{Lsd}(5 \%)$ & 5.43 & 2.61 & 6.28 & 14.28 & 3.40 & 2.01 & 1.12 \\
\hline & CV (\%) & 4.99 & 1.16 & 5.41 & 9.49 & 5.19 & 1.55 & 12.66 \\
\hline
\end{tabular}

\#you have to see Table 3. For Abbreviations.

\subsection{Estimates of the Variance Components}

Estimates of the variance components for thirteen genotypes with seven traits. The detail information's are presented in Table 5.

\subsubsection{Estimations of Phenotypic and Genotypic Coefficient}

According to [13], the phenotypic and genotypic coefficients of variation revealed that thousand kernel weight and grain yield had a wide range of PCV and GCV, whereas plant height had a moderate PCV value (Table 5). Similar findings were reported by earlier researchers for 1000 grain weight $[1,2]$; for grain yield $[24,25,35]$.

Through this studied, low GCV and PCV reported by earlier researchers for days to heading, [5, 25, 36]; days to maturity $[5,24,25,36]$; grain filling period $[5,8,25,36]$; and hectoliter weight [5, 24, 25].

Days to heading and days to maturity, gain filling period, and hectoliter weight all had slightly greater phenotypic coefficients of variation than genotypic coefficients of variation, indicating that those traits were less impacted by the environment. Grain yield, thousand kernel weight, and plant height, on the other hand, were shown to have a higher phenotypic coefficient of variation than genotypic coefficient of variation, indicating that they were more influenced by the environment.

\subsubsection{Estimation of Heritability and Genetic Advance}

According to [33] heritability estimations, thousand kernel weights $(81.14 \%)$ have a very high heredity estimate, whereas days to heading (43.93), days to maturity $(51.33 \%)$, hectoliter weight $(57.51 \%)$, and grain yield have moderate heritability estimates $(41.77 \%)$. Low values of broad sense heritability were revealed; plant height $(24.48 \%)$ and grain filling period $(25.31 \%)$.

Previous studies [1, 2, 24] found very high estimates of broad sense heritability. Previous researchers have reported medium estimates of broad sense heredity for days to heading [14], days to maturity [38], hector liter weight [11, $25]$, and grain yield $[5,25,28]$. Low estimates of broad sense heritability also reported by previous researchers for grain filling period $[1,14,26]$.

Heritability values can be used to forecast the predicted development of a selection process. Traits with high heritability estimates might respond effective to selection since it expected that, environment expression on phenotypic expression is low. Thus indicates higher relative magnitude of genotypic variance for the total variations among the studied genotypes with respective high heritability traits. Therefore, based on their phenotypic expression selection on high and very high broad sense heritability may be respond effective because it is expected that traits with high heritability estimate have a close correlation between phenotypic and genotypic appearance.

Heritability does not determine the amount of genetic improvement that would result from individual genotype selection. As a result, heredity information combined with genetic progress is more valuable. Genetic advance (GA) under selection refers to the improvement of features in genotypic value for the new population relative to the base population for one cycle of selection at a certain selection intensity [33]. Genetic advance (GA) is also important for estimating the projected genetic gain after one cycle of selection, according to [20]. The estimated GA values for all of the characters studied are shown in (Table 5). Comparable findings also stated by $[2,24]$.

For grain yield, the genetic advance as a percentage of the mean projections was moderate $(14.32 \%)$.

Days to heading $(6.05 \%)$, days to maturity $(1.76 \%)$, plant height $(5.51 \%)$, grain filling period $(3.27 \%)$, and hectoliter weight all had low estimates of genetic advance as a percentages $(2.82 \%)$.

Similar results reported for grain yield [1, 25, 28]; days to heading $[5,38,28,36]$, days to maturity $[5,11,14,24,26$, $28,38]$ plant height $[5,11]$ and grain filling period $[5,14,26$, $38]$ and hectoliter weight $[5,11,24,25]$.

The features with high heritability and high genetic progress as a percentage of the mean, such as 1000 kernel weight, suggest that selection for enhancement of these characters could be fruitful. Similar agreement with also reported by previous researchers 1000 kernel weight [12]. 
For grain filling period and plant height, low heritability and poor genetic progress as a percentage of the mean were identified. The expression of economically importance characters through additive gene action make selection for crop improvement might be satisfying. This is supported by a high wide sene heritability value and a strong genetic progress as a percentage of the mean [29].

Table 5. Estimates of the Variance Components for different quantitative traits in bread wheat genotypes.

\begin{tabular}{|c|c|c|c|c|c|c|c|c|c|c|}
\hline \multirow{2}{*}{ Traits } & \multirow{2}{*}{ Mean } & \multicolumn{2}{|l|}{ Range } & \multirow{2}{*}{$\delta^{2} g$} & \multirow{2}{*}{$\delta^{2} p$} & \multirow{2}{*}{ GCV (\%) } & \multirow{2}{*}{ PCV (\%) } & \multirow{2}{*}{$H^{2}(\%)$} & \multirow{2}{*}{ GA } & \multirow{2}{*}{ GA (\%) } \\
\hline & & Min & Max & & & & & & & \\
\hline DTH & 65.98 & 57.00 & 74.30 & 8.52 & 19.40 & 4.42 & 6.68 & 43.93 & 3.99 & 6.05 \\
\hline DTM & 136.42 & 133.33 & 140.67 & 2.65 & 5.16 & 1.19 & 1.66 & 51.33 & 2.40 & 1.76 \\
\hline GFP & 70.44 & 63.67 & 77.67 & 4.92 & 19.45 & 3.15 & 6.26 & 25.31 & 2.30 & 3.27 \\
\hline PHT & 91.37 & 58.33 & 100.53 & 24.37 & 99.55 & 5.40 & 10.92 & 24.48 & 5.04 & 5.51 \\
\hline TKW & 39.83 & 26.88 & 54.50 & 18.37 & 22.64 & 10.76 & 11.95 & 81.14 & 7.96 & 20.00 \\
\hline GYLD & 5.35 & 3.17 & 6.85 & 0.33 & 0.79 & 10.74 & 16.61 & 41.77 & 0.77 & 14.32 \\
\hline
\end{tabular}

Where: $\delta^{2} \mathrm{p}=$ Phenotypic variance, $\delta^{2} \mathrm{~g}=$ Genotypic variance, $\mathrm{PCV}=$ phenotypic coefficient of variance, $\mathrm{GCV}=\mathrm{Genotypic}$ coefficient of variation, $\mathrm{H}^{2}=\mathrm{Broad}$ sense heritability, GA= genetic advance, GAM $(\%)=$ Genetic advance as percent of mean. You have to see Table 3. For Abbreviations.

\section{Conclusion}

Different variables provide genetic heterogeneity among the studied types, which is useful for direct and indirect selection. Attention should be paid to traits with moderate to high variability and genetic advancement in order to produce an effective response to yield enhancement. The genotypes examined qualities' variability and heritability confirmed the likelihood of boosting wheat productivity in the target area. For further bread wheat yield enhancement in a specific area, selection and hybridization on genotypes with high GCV, heritability, and genetic advance on yield can be recommended.

\section{Acknowledgements}

I recognized Ethiopian Institute of Agricultural Research for the source of budget to conduct this research trial. Secondly, I would like thanks to the member of wheat improvement staff of Holetta Agricultural Research Center their help during field data collection.

\section{References}

[1] Adhiena, M., Wassu, M. and Taddesse, D., 2016. Estimation of heritability and genetic advance of yield and yield related traits in bread wheat (Triticum aestivum L.) genotypes at Ofla District, Northern Ethiopia. International Journal of Plant Breeding and Genetics, 10 (1), pp. 31-37.

[2] Ali, Y., Atta, B. M., Akhter, J., Monneveux, P. and Lateef, Z., 2008. Genetic variability, association and diversity studies in wheat (Triticum aestivum L.) germplasm. Pak. J. Bot, 40 (5), pp. 2087-2097.

[3] Allard, R. W., 1960. Principles of plant breeding. John Willey and Sons. Inc. New York, 485.

[4] Awale, D. Takele, D. and, Mohammed, Sh. 2013. Genetic variability and traits association in bread wheat (Triticum aestivum L.) genotypes. International Research Journal of Agricultural Sciences, 1 (2): 19-29.
[5] Bayisa, T., Tefera, H. and Letta, T., 2020. Genetic variability, heritability and genetic advance among bread wheat genotypes at Southeastern Ethiopia. Agriculture, Forestry and Fisheries, 9 (4), p. 128.

[6] Bekele H, Verkuiji W, Mawangi T. (2000). Adaptation of improved heat technologies in Addaba and Doddola Worede's of the Bale highlands of Ethiopia. CIMMYT/EARO, Addis Ababa, Ethiopia.

[7] Bezabeh E. (2015). Change and growth rate analysis in area, yield and production of wheat in Ethiopia. Research Journal of Agriculture and Environmental Management. 4 (4), 189-191.

[8] Bhushan, B., Gaurav, S. S., Kumar, R., Pal, R., Panday, M., Kumar, A., Bharti, S., Nagar, S. S. and Rahul, V. P., 2013. Genetic variability, heritability and genetic advance in bread wheat (Triticum aestivum L.). Environment \& Ecology, 31 (2), pp. $405-407$.

[9] Burton, G. W., and Devane, E. H., 1953. Estimating heritability in tall fescue from Replicated clone natural materials. Agronomy Journal, 45: 171-181.

[10] Clarke, F. R., Clarke, J. M., Ames, N. A., Knox, R. E. and Ross, R. J., 2010. Gluten index compared with SDS-sedimentation volume for early generation selection for gluten strength in durum wheat. Canadian Journal of Plant Science, 90 (1), pp. 1-11.

[11] Dabi, A., Mekbib, F. and Desalegn, T., 2019. Genetic variability studies on bread wheat (Triticum aestivum L.) genotypes. Journal of Plant Breeding and Crop Science, 11 (2), pp. 41-54.

[12] Dargicho, D., Sentayehu, A., Firdisa, E. and Ermias, A., 2015. Genetic variability in bread wheat (Triticum aestivum L.) germplasm for yield and yield component traits. Journal of Biology, Agriculture and Healthcare, 5 (17), pp. 140-147.

[13] Deshmukh, S. N., Basu, M. S. and Reddy, P. S., 1986. Genetic variability, character association and path coefficients of quantitative traits in Virginia bunch varieties of groundnut. Indian Journal of Agricultural Sciences.

[14] Delta M, Shiferaw A and Zerga, 2020. Study of genetic variability in some bread wheat accessions (Triticum aestivum L.) in Gurage zone, Ethiopia. Asian J. Biol. Sci., 13: 309-317.

[15] Falconer, D. S. (1981). Introduction to quantitative genetics. Ed. 2. Longmans Green, London/ New York. 
[16] Falconer, D. S., Mackay, T. F. and Frankham, R., 1996. Introduction to quantitative genetics: trends in genetics. Harlow: Longman Frankel, 12 (7), p. 280.

[17] FAOSTAT. (2018). FAOSTAT statistical database Accessed 16 July 2018. www.fao.org/faostat/.

[18] Fikre, G., Alamerew, S. and Taddesse, Z., 2015. Genetic variability studies in bread wheat (Triticum aestivum L.) genotypes at Kulumsa agricultural research center, south east Ethiopia.

[19] Gezahegn, F., Sentayehu, A. and Zerihun, T., 2015. Genetic Variability Studies in Bread Wheat (Triticum aestivum L.) Genotypes at Kulumsa Agricultural Research Center, South East Ethiopia. Journal of Biology, Agriculture and Health care, 5 (7): 89-98.

[20] Hamdi, A., Ghareib, A. A., Shafey, S. A. and Ibrahim, M. A. M., 2003. Genetic variability, heritability and expected genetic advance for earliness and seed yield from selection in lentil. Egyptian Journal of Agricultural Research, 81: 125-138.

[21] Johnson, H. W., Robinson, H. F. and Comstock, R. E., 1955. Estimates of genetic and environmental variability in soybeans 1. Agronomy journal, 47 (7), pp. 314-318.

[22] Letta T., 2013. Association mapping reveals novel stem rust resistance loci in durum wheat at the seedling stage. The Plant Genome: doi: 10.3835/plant genome, 2013. 08.00.

[23] Majumder, D. A. N., Shams Uddin, A. K. M., Kabir, M. A. and Hassan, L. 2008. Genetic variability, correlated response and path analysis of yield and yield contributing traits of spring wheat. Journal of Bangladesh Agricultural University, 6 (2): $227-234$

[24] Mecha, B., Alamerew, S., Assefa, A., Dutamo, D. and Assefa, E., 2016. Correlation and path coefficient studies of yield and yield associated traits in bread wheat (Triticum aestivum L.) genotypes. Adv. Plants Agric Res, 6 (5), pp. 1-10.

[25] Meles, B., Mohammed, W. and Tsehaye, Y., 2017. Genetic variability, correlation and path analysis of yield and grain quality traits in bread wheat (Tritium aestivum L.) genotypes at Axum, Northern Ethiopia. Journal of plant breeding and crop science, 9 (10), pp. 175-185.

[26] Muhder, N., Gessese, M. K. and Sorsa, Z., 2020. Assessment of genetic variability among agronomic traits and grain protein content of elite bread wheat (Triticum aestivum L.) genotypes in the central highlands of Ethiopia. Asian J. Agric. Res., 14: 1-12.

[27] Obsa, Ch. Wassu, W. and Firdissa, E., 2017. Analysis of Genetic Variability among Bread Wheat (Triticum aestivum L.) Genotypes for Growth, Yield and Yield Components in Bore District, Oromia Regional State. Agriculture, Forestry and Fisheries, 6 (6): 188 - 199.
[28] Pachauri, P., Kandalkar, V. S. and Satankar, N., 2018. Analysis of genetic variability and path coefficient for yield and yield contributing traits in cultivated and synthetic wheat and their interspecific crosses. Journal of Pharmacognosy and Phytochemistry, 7, pp. 83-87.

[29] Raia, P. K., Sarkara, U. K., Islamb, A. S., Bahaman, M. A. and Hasan. M., 2016. Genetic study and selection in the F4 generation of rice (Oryza. sativa L.). Journal of Bioscience and Agriculture Research, 9 (01): 768-774.

[30] SAS. 2012. Statistical analysis system, version 9.3 editions. SAS Institute Inc. Cary, NC.

[31] Sears ER. (1966). Nullisomic tetratomic combinations in wheat. In: R Riley, KR Lewis, eds. Chromosome Manipulation and Plant Genetics. Oliver and Boyd, Edinburgh. pp 29-45.

[32] Shukla, S., Bhargava, A., Chatterjee, A. and Singh, S. P., 2004. Estimates of genetic parameters to determine variability for foliage yield and its different quantitative and qualitative traits in vegetable amaranth (A. tricolor) [India]. Journal of Genetics and Breeding (Italy), 58, 169-176.

[33] Singh, B., 2001. Plant Breeding: Principles and Methods, 6th ed., Kalyani Publishers, New Delhi, India.

[34] Tamene, T. Keneni, G. and Mohammad, H., 2015. Genetic progresses from over three decades of faba bean ('Vicia faba L.) breeding in Ethiopia. Australian Journal of Crop Science, 9 (1), pp. 41-48.

[35] Taneva, K., Bozhanova, V., \& Petrova, I. (2019). Variability, heritability and genetic advance of some grain quality traits and grain yield in durum wheat genotypes. Bulgarian Journal of Agricultural Science, 25 (2), 288-295.

[36] Ullah, K., Khan, S. J., Muhammad, M. I. T. and Muhammad, S., 2011. Genotypic and phenotypic variability, heritability and genetic diversity for yield components in bread wheat (Triticum aestivum L.) germplasm. African Journal of Agricultural Research, 6 (23), pp. 5204-5207.

[37] Zecevic, V., Knezevic, D., Micanovic, D., Urosevic, D., Dimitrijevic, B. and Urosevic, V., 2001. Components of variance and heritability of quality parameters in wheat cultivars. Genetika, 13 (3), pp. 77-84.

[38] Zerga, K., Mekbib, F. and Desalegn, T., 2016. Estimation of association among growth and yield related traits in bread wheat (Triticum aestivum. L) Genotypes at Gurage Zone, Ethiopia. International Journal of Plant Breeding and Crop Science, 3 (2), pp. 123-134. 